This is the accepted version of the following article

Roman Svoboda, Jiří Málek, Marek Liška (2019). Correlation between the structure and structural relaxation data for (GeSe2)y(Sb2Se3)1-y glasses. Journal of Non-Crystalline Solids. DOI:

10.1016/j.jnoncrysol.2018.11.013

This accepted version is available from URI https://hdl.handle.net/10195/74731

Publisher's version is available from:

https://www.sciencedirect.com/science/article/pii/S0022309318306689?via\%3Dihub

\title{
(c) $(\mathrm{BY})$
}

This version is licenced under a Creative Commons Attribution-NonCommercial-NoDerivatives 4.0.International. 


\title{
Correlation between the structure and structural relaxation data for
}

\author{
$\left(\mathrm{GeSe}_{2}\right)_{\mathrm{y}}\left(\mathrm{Sb}_{2} \mathrm{Se}_{3}\right)_{1-\mathrm{y}}$ glasses
}

Roman Svoboda ${ }^{*}$, Jiří Málek ${ }^{\mathrm{a}}$, Marek Liška ${ }^{\mathrm{b}}$

${ }^{a}$ University of Pardubice, Faculty of Chemical Technology, Department of Physical Chemistry, Studentská 573, 53210 Pardubice, Czech Republic.

${ }^{b}$ Vitrum Laugaricio - Joint Glass Center of IIC SAS, TnUAD, FChPT STU, Studentská 2, 91101 Trenčín, Slovakia

\begin{abstract}
Combined calorimetric and structural study, employing the techniques of differential scanning calorimetry and Raman spectroscopy, was performed to describe the enthalpy relaxation processes in the $\left(\mathrm{GeSe}_{2}\right)_{\mathrm{y}}\left(\mathrm{Sb}_{2} \mathrm{Se}_{3}\right)_{1-\mathrm{y}}$ chalcogenide glasses. The full glass forming compositional region $(y=0.3-0.9)$ was explored. The enthalpy relaxation was described in terms of the phenomenological Tool-Narayanaswamy-Moynihan model. Compositional evolution of the glass transition temperatures and relaxation activation energies was explained based on the changing average bond energies and overall interconnectivity of the glassy matrices. Resemblance between the activation energies of the relaxation processes and viscous flow was confirmed for all studied glasses. Non-linearity and non-exponentiality of the enthalpy relaxation were found to be invariant with composition. The structural relaxation kinetics as well as kinetic fragilities determined for the present $\left(\mathrm{GeSe}_{2}\right)_{\mathrm{y}}\left(\mathrm{Sb}_{2} \mathrm{Se}_{3}\right)_{1-\mathrm{y}}$ glassy system were very similar to the results obtained earlier for the $\left(\mathrm{GeS}_{2}\right)_{y}\left(\mathrm{Sb}_{2} \mathrm{~S}_{3}\right)_{1-\mathrm{y}}$ glasses, which can be attributed to the similarly constrained topology of the pseudo-binary compositional lines.
\end{abstract}

Keywords: enthalpy relaxation, TNM model, Raman spectroscopy, DSC, Ge-Sb-Se glasses

\footnotetext{
${ }^{*}$ Corresponding author: Tel.: +420 466037346 E-mail address: roman.svoboda@ @upce.cz
} 


\section{Introduction}

Glass transition belongs among the most important thermo-kinetic phenomena studied for chalcogenide glasses. The kinetics of glass transition enables prediction of the glass transition position $\left(\mathrm{T}_{\mathrm{g}}\right)$ for different thermal histories (which is utilizable e.g. for glass processing or estimating lifetime of glassy components in various hi-tech devices), defines impact of structural movements on the glass compactness and determines glass stability. The Ge-Sb-Se glasses can be potentially utilized in a number of optical and electrical applications [1-10], such as optical signal processing based on nonlinear effects for telecommunication systems, photolithography, construction of optical elements for IR laser optics, or chemical sensing. Regarding the thermo-kinetic and thermo-structural behavior of the $\left(\mathrm{GeSe}_{2}\right)_{\mathrm{y}}\left(\mathrm{Sb}_{2} \mathrm{Se}_{3}\right)_{1-\mathrm{y}}$ glasses, the glass formation in these glasses is relatively well known [1113], the glasses along this compositional line can be prepared by the conventional meltquenching for $\mathrm{y}=0.3-1.0$. The crystallization behavior was studied several times for bulk glasses as well as for the thin films, showing the transition between the formation of $\mathrm{Sb}_{2} \mathrm{Se}_{3}$ and $\mathrm{GeSe}_{2}$ crystallites as the composition changes from Sb-rich to Ge-rich. [14-18] The structure of the $\left(\mathrm{GeSe}_{2}\right)_{\mathrm{y}}\left(\mathrm{Sb}_{2} \mathrm{Se}_{3}\right)_{1-\mathrm{y}}$ glasses is also known - number of Raman spectroscopy studies are published. [19-21] However, despite the $\left(\mathrm{GeSe}_{2}\right)_{\mathrm{y}}\left(\mathrm{Sb}_{2} \mathrm{Se}_{3}\right)_{1-\mathrm{y}}$ glasses being the corner-stone for chalcogenide science, there are practically no information on the glass transition kinetics of these glasses.

In the present article the structural relaxation behavior of $\left(\mathrm{GeSe}_{2}\right)_{y}\left(\mathrm{Sb}_{2} \mathrm{Se}_{3}\right)_{1-y}$ glasses (for $y=0.3-0.9$ ) will be investigated by means of differential scanning calorimetry DSC; the enthalpy relaxation data will be further compared to the previously studied viscosity [22] and Raman spectroscopy [19-21] data in order to correlate the activation energies of the relaxation movements and viscous flow via the fragility concept. In addition, the data will be compared 
to our previous (similar) study on the sulfide $\left(\mathrm{GeS}_{2}\right)_{\mathrm{y}}\left(\mathrm{Sb}_{2} \mathrm{~S}_{3}\right)_{1-\mathrm{y}}$ glassy system [23], so that the influences of Se and S atoms on the structural movements can be identified.

\section{Experimental}

The $\left(\mathrm{GeSe}_{2}\right)_{\mathrm{y}}\left(\mathrm{Sb}_{2} \mathrm{Se}_{3}\right)_{1-\mathrm{y}}$ glasses (for $\mathrm{y}=0.3-0.9$ ) were prepared from the pure elements (5N, Sigma Aldrich) by the standard melt-quenching technique - i.e. the proper amount of elements were inserted into a fused silica ampoule, which was then evacuated, sealed, melted at $950{ }^{\circ} \mathrm{C}$ for 48 hours, and quenched in water. Part of each glassy ingot was ground (using an agate mortar) to a powder with $125-180 \mu \mathrm{m}$ particle size. Amorphous character of the bulk and powdered glasses was confirmed by X-ray diffraction (Bruker AXS diffractometer D8 Advance equipped with a horizontal goniometer and scintillation counter utilizing $\mathrm{CuK}_{\alpha}$ radiation was used). Compositional and structural homogeneity of the bulk and powdered glasses was verified by Raman spectroscopy - the DXR2 Raman microscope (Nicolet, Thermo Fisher Scientific), utilizing the $785 \mathrm{~nm}$ excitation diode laser (1 mW, laser spot size $1.6 \mu \mathrm{m}, 90$ scans $\rightarrow 5 \mathrm{~s}$ each) and CCD detector, was used. In addition, the structural integrity of the prepared glassy ingots was confirmed also based on the consistent position of the relaxation peak measured by DSC under defined conditions for several bulk samples taken from various places from each as-prepared glassy ingot. The glass transition kinetics was studied by the Q2000 DSC (TA Instruments) equipped with cooling accessory, autolid, autosampler, and T-zero Technology. Dry nitrogen was used as the purge gas at a rate of 50 $\mathrm{cm}^{3} \cdot \mathrm{min}^{-1}$. The calorimeter was calibrated based on the melting temperatures of In, Zn, and $\mathrm{H}_{2} \mathrm{O}$. Sample masses were between 8 and $10 \mathrm{mg}$ for both powders and bulk samples (the latter were realized by breaking a piece of glass off of a thin sheet of glass formed on the inner ampoule wall). 
The DSC relaxation experiments were performed in a standard way, for each prepared $\left(\mathrm{GeSe}_{2}\right)_{\mathrm{y}}\left(\mathrm{Sb}_{2} \mathrm{Se}_{3}\right)_{1-\mathrm{y}}$ glass a set of constant ratio (CR) cycles [24, 25] was done in the glass transition region. In particular, the CR3 modification was employed, where each cooling step through $\mathrm{T}_{\mathrm{g}}$ (performed at following cooling rates: $0.5,1,2,3,5,7,10,15,20$, and $30{ }^{\circ} \mathrm{C} \cdot \min ^{-}$ ${ }^{1}$ ) was followed by a heating step at rate three times larger than the cooling rate. Moreover, one set of constant heating rate (CHR) cycles [26, 27] was performed for each studied glassy composition. Again, the CHR3 variant was employed, where each cooling step through $\mathrm{T}_{\mathrm{g}}$ (performed at cooling rates $0.5,1,2,3,5,7,10,15,20$, and $30{ }^{\circ} \mathrm{C} \cdot \mathrm{min}^{-1}$ ) was always followed by a heating step of $30^{\circ} \mathrm{C} \cdot \mathrm{min}^{-1}$ (the standard option for this type of cyclic thermal history is $\mathrm{q}^{+}=10{ }^{\circ} \mathrm{C} \cdot \mathrm{min}^{-1}$, hence the CHR3 modification). To minimize the measurement errors, each set of cycles was performed using the same glassy sample, which was not removed from the DSC cell. At the end of each set of cycles one additional cycle with $\mathrm{q}^{-}=10^{\circ} \mathrm{C} \cdot \mathrm{min}^{-1}$ to verify the repeatability of the measurements and to confirm that the glassy sample did not degrade (crystallize) during the heat treatment. The temperature ranges in which the cycles were performed are for all studied glasses listed in Table 1.

Regarding the error analysis, characteristic DSC temperatures $\left(T_{g}, T_{p}\right)$ as well as the Raman data were perfectly reproducible - the errors were lower than the magnitude of points in the corresponding graphs. Good reproducibility of the DSC data from CHR cycles was confirmed based repeating selected cycles - the errors of evaluated TNM parameters will correspond to their variability with experimental evaluations, i.e. $\mathrm{q}^{+} / \mathrm{q}^{-}$ratio.

\section{Results}

Example of the obtained DSC relaxation curves is shown in Fig. 1. The data exhibited all the typical features associated with hysteresis, non-linearity and non-exponentiality of the glass transition kinetics. [28, 29] The set of CHR cycles (Fig. 1A) obtained for the 
$\left(\mathrm{GeSe}_{2}\right)_{0.4}\left(\mathrm{Sb}_{2} \mathrm{Se}_{3}\right)_{0.6}$ composition shows the typical increase in magnitude and shift to higher temperatures for the relaxation peaks obtained at same $\mathrm{q}^{+}$following cooling steps at decreasing $\mathrm{q}^{-}$. Note the overlapping parts of the heating scans in the glassy and undercooled liquid areas, which indicate the high reproducibility of the DSC signal (as a result of a single sample being used for all the cycles within the given set). The set of CR cycles for the $\left(\mathrm{GeSe}_{2}\right)_{0.4}\left(\mathrm{Sb}_{2} \mathrm{Se}_{3}\right)_{0.6}$ composition is depicted in Fig. 1B - the increased heating rate during the particular scans results in the typical shift of the characteristic temperatures to higher $\mathrm{T}$ (as well as the overall amplification of the signal, as is inherent for the DSC heat flow measurements). Note the unfinished evolution of the relaxation peak at highest heating rate this is intentional in order to reduce the highest achieved temperature and thus reduce the danger of sample degradation (this will be in detail discussed in section 4).

The compositional evolution of the glass transition temperature in the $\left(\mathrm{GeSe}_{2}\right)_{\mathrm{y}}\left(\mathrm{Sb}_{2} \mathrm{Se}_{3}\right)_{1-\mathrm{y}}$ chalcogenide system is shown in Fig. 1C for two selected heating rates, together with the data for the structurally akin sulfide - $\left(\mathrm{GeS}_{2}\right)_{\mathrm{y}}\left(\mathrm{Sb}_{2} \mathrm{~S}_{3}\right)_{1-\mathrm{y}}[23]$ - counterpart. A very similar trend can be noticed for the two pseudo-binary compositional lines, which is associated with the increase of higher-melting $\mathrm{GeSe}_{2} / \mathrm{GeS}_{2}$ component. In addition, the similar (and similarly decreasing) difference between the $\mathrm{T}_{\mathrm{g}}$ values obtained at $1{ }^{\circ} \mathrm{C} \cdot \mathrm{min}^{-1}$ and $10{ }^{\circ} \mathrm{C} \cdot \mathrm{min}^{-1}$, indicates similar absolute values (and their evolution) of the process activation energy for selenide and sulfide glasses. The slightly higher $\mathrm{T}_{\mathrm{g}}$ values of the sulfide analogue are consequence of the higher bond energies: Ge-Se $230 \mathrm{~kJ} \cdot \mathrm{mol}^{-1}$, Sb-Se $215 \mathrm{~kJ} \cdot \mathrm{mol}^{-1}$, Ge-S $265 \mathrm{~kJ} \cdot \mathrm{mol}^{-1}, \mathrm{Sb}-\mathrm{S} 230 \mathrm{~kJ} \cdot \mathrm{mol}^{-1} \cdot[30,31]$

Compositional evolution of the actual enthalpy relaxation kinetics is then depicted in Fig. 1D, where the raw CHR cycles data for the heating scan following cooling at $1{ }^{\circ} \mathrm{C} \cdot \mathrm{min}^{-1}$ are shown for each studied $\left(\mathrm{GeSe}_{2}\right)_{y}\left(\mathrm{Sb}_{2} \mathrm{Se}_{3}\right)_{1-\mathrm{y}}$ material. Unfortunately, due to the complex glass transition kinetics and its consequences toward the shape of the relaxation peak, no 
reliable interpretation regarding the evolution of the relaxation parameters can be made based on a simple visual comparison such as the one depicted in Fig. 1D and proper kinetic analysis is needed in order to reveal the involvement of the particular relaxation features. For example, in case of the $\left(\mathrm{GeS}_{2}\right)_{y}\left(\mathrm{Sb}_{2} \mathrm{~S}_{3}\right)_{1-\mathrm{y}}$ glasses a very similar complicated evolution of relaxation peak shapes was observed [23], but the consequent analysis has shown that all these changes can be attributed solely to the variance in relaxation activation energy and that the magnitude of the non-linearity and non-exponentiality features was similar along the whole compositional line.

The Raman spectroscopy was employed to provide the structural information that could be associated with the relaxation movements - see Fig. 2. The structural arrangements in the $\left(\mathrm{GeSe}_{2}\right)_{\mathrm{y}}\left(\mathrm{Sb}_{2} \mathrm{Se}_{3}\right)_{1-\mathrm{y}}$ glasses are well known [19-21] and the present Raman spectra are identical to those reported in [6], hence rather brief structural analysis will be given here, with the emphasis on the information that will be later needed for interpretation of the relaxation kinetics. The following assignments can be recognized in the Raman spectra: band at $100 \mathrm{~cm}^{-}$ ${ }^{1} \sim$ umbrella vibration in $\mathrm{SbSe}_{3 / 2}$ pyramids [32-34], band at $150 \mathrm{~cm}^{-1} \sim \mathrm{Sb}-\mathrm{Sb}$ vibration in $\mathrm{Se}_{2} \mathrm{Sb}_{-} \mathrm{SbSe}_{2}$ [32-34], band at $170 \mathrm{~cm}^{-1} \sim \mathrm{Ge}-\mathrm{Ge}$ vibration in $\mathrm{Ge}-\mathrm{Se}_{4-\mathrm{n}} \mathrm{Ge}_{\mathrm{n}}$ [33, 35-37], band at $190 \mathrm{~cm}^{-1} \sim$ Sb-Se stretch vibration in $\mathrm{SbSe}_{3 / 2}$ pyramids $[33,34,38]$, band at $200 \mathrm{~cm}^{-1} \sim$ symmetric stretch vibration of corner-shared $\mathrm{GeSe}_{4 / 2}$ tetrahedra $[32,33,38]$, band at $215 \mathrm{~cm}^{-1}$ $\sim$ breath vibration of edge-shared $\mathrm{GeSe}_{4 / 2}$ tetrahedra [36-38], bands at $235-250 \mathrm{~cm}^{-1} \sim$ various vibrations of Se structural units $[32,35,37]$, band at $265 \mathrm{~cm}^{-1} \sim$ vibrations of cornershared $\mathrm{GeSe}_{4 / 2}$ tetrahedra positioned in dimers or short chains [32, 33, 38], band at 285 $300 \mathrm{~cm}^{-1} \sim$ asymmetric vibration of $\mathrm{GeSe}_{4 / 2}$ tetrahedra [36-38].

The Raman spectra were deconvoluted in accordance with [6]. The preset positions of the peaks over the main complex band are shown in Fig. 3A and correspond to the abovelisted assignments. In addition to these deconvolution positions the two additional broad 
bands at $50-125 \mathrm{~cm}^{-1}$ (further denoted as vibration at $100 \mathrm{~cm}^{-1}$ ) and $250-325 \mathrm{~cm}^{-1}$ (further denoted as vibration at $265 \mathrm{~cm}^{-1}$ ) were included in the optimization, although they exhibit almost no overlap with the main complex band situated between 125 and $250 \mathrm{~cm}^{-1}$. The compositional evolution of the integral areas corresponding to the individual deconvoluted Raman bands are shown in Figs. 3B and 3C - note that the $100 \%$ integral area corresponds to the full Raman spectrum between 50 and $350 \mathrm{~cm}^{-1}$. As is apparent from Fig. 3, the integral area corresponding to the corner-shared $\mathrm{GeSe}_{4 / 2}$ tetrahedra $\left(200 \mathrm{~cm}^{-1}\right)$ is constant over the explored compositional range. Regarding the homopolar bonds, the significant increase of the $\mathrm{Ge}_{-} \mathrm{Se}_{4-\mathrm{n}} \mathrm{Ge}_{\mathrm{n}}+\mathrm{Ge}_{2} \mathrm{Se}_{6 / 2}$ band intensity $\left(170 \mathrm{~cm}^{-1}\right)$ with increasing $\mathrm{Sb}_{2} \mathrm{Se}_{3}$ content indicates clustering of $\mathrm{Ge}$ at higher $\mathrm{Sb}_{2} \mathrm{Se}_{3}$ contents (similar to what was observed in [6]); this trend appears to be accompanied (and compensated) by the decrease of the $265 \mathrm{~cm}^{-1}$ and 285 $300 \mathrm{~cm}^{-1}$ vibrations of the $\mathrm{CS}-\mathrm{GeSe}_{4 / 2}$ tetrahedra positioned in dimers or short chains. Also note the gradually decreasing presence of the Sb-Se stretch vibrations (accompanied by the increase in the umbrella vibrations of the $\mathrm{SbSe}_{3 / 2}$ pyramids) occurring with the decreasing $\mathrm{Sb}_{2} \mathrm{Se}_{3}$ content.

In addition to the standard Raman spectra measurements performed for the asprepared samples, the temperature-resolved experiments were carried out in order to reveal the changes of structural arrangements during the relaxation process. For samples of each composition two temperature histories were implemented. One sample was shortly annealed at temperature above $\mathrm{T}_{\mathrm{g}}$ (the temperature was considered also with respect to the crystallization of each composition [14-18], so that no degradation occurred during the annealing) and then quenched to the laboratory temperature to preserve the most of the high-T undercooled liquid structure. Second sample was slowly cooled approx. $15{ }^{\circ} \mathrm{C}$ below $\mathrm{T}_{\mathrm{g}}$, annealed at that temperature for 48 hours to achieve the new structural equilibrium, and then quenched. Each sample was measured immediately after the preparation. The selected Raman 
spectra corresponding to the two typical cases of observed structural changes are shown in Fig. 3D. For higher $\mathrm{GeSe}_{2}$ contents $(y=0.6-0.9$ tested presently, but very probably up to 1.0) the relaxation changes are clearly reflected by the increased CS/ES ratio of the $\mathrm{GeSe}_{4 / 2}$ tetrahedra (with no changes being observed for the Sb-based structural units); i.e. major portion of the structural relaxation movements dwells in the formation of the stabilized CS$\mathrm{GeSe}_{4}$ network. In case of the compositions with $\mathrm{y}=0.4$ and 0.5 no change between the quenched and sub- $\mathrm{T}_{\mathrm{g}}$ annealed spectra was observed. For the $\left(\mathrm{GeSe}_{2}\right)_{0.3}\left(\mathrm{Sb}_{2} \mathrm{Se}_{3}\right)_{0.7}$ glass it seems that the structural relaxation involves again formation of additional $\mathrm{CS}-\mathrm{GeSe}_{4}$ and $\mathrm{Ge}_{2} \mathrm{Se}_{6 / 2}$ structural units, possibly at the expense of the CS-GeSe $4 / 2$ tetrahedra positioned in dimers or short chains. In addition, the structural relaxation appears to be also accompanied by the slight changes in the intensities of $\mathrm{SbSe}_{3 / 2}$ pyramidal vibrations - increase of the stretch one and decrease of the umbrella one. Note, however, that the conclusions for the $\left(\mathrm{GeSe}_{2}\right)_{0.3}\left(\mathrm{Sb}_{2} \mathrm{Se}_{3}\right)_{0.7}$ composition need to be taken with a pinch of salt due to the significantly higher noise in the data.

\section{Discussion}

In order to explain the compositional evolution of the glass transition behavior reported in Fig. 1 and to associate it with the structural information provided by Raman spectroscopy, the kinetics of the structural relaxation was described in terms of the phenomenological Tool-Narayanaswamy-Moynihan model [39-41] (with Eq. 1 optimized for the DSC data):

$$
\begin{gathered}
C_{p}^{r e d}=\frac{d T_{f}}{d T}=\frac{C_{p}-C_{p g}}{C_{p l}-C_{p g}} \\
C_{p}^{r e d}(t)=\exp \left[-\left(\int_{0}^{t} \frac{d t}{\tau\left(T, T_{f}\right)}\right)^{\beta}\right]
\end{gathered}
$$




$$
\tau\left(T, T_{f}\right)=A_{T N M} \cdot \exp \left[x \frac{\Delta h^{*}}{R T}+(1-x) \frac{\Delta h^{*}}{R T_{f}}\right]
$$

where $T_{f}$ is the so-called fictive temperature (expressing the state of the relaxing glass structure), $\tau$ is relaxation time, $\Delta \mathrm{h}^{*}$ is apparent activation energy of the relaxation processes, $A$ is the pre-exponential term, $x$ is the nonlinearity parameter $(0<x \leq 1)$ and $\beta$ is the nonexponentiality parameter $(0<\beta \leq 1)$. The fictive temperature is used for calculation of the normalized heat capacity $C_{p}{ }^{\text {red }}$ via the extrapolations of $C_{p l}$ and $C_{p g}$ (sample heat capacities in the undercooled liquid and glassy states, respectively).

The most important quantity of the above-introduced model terminology is the relaxation activation energy $\Delta \mathrm{h}^{*}$. It was proved recently [26, 29] (based on the theoretically simulated data) that one of the most suitable methodologies for evaluation of this quantity is the newly developed [25] equation based on the shift of the maximum of the relaxation peak $\mathrm{T}_{\mathrm{p}}$ with applied cooling rate during the $\mathrm{CR}$ cycles:

$$
-\frac{\Delta h^{*}}{R}=\left[\frac{d \ln \left|q^{-}\right|}{d\left(1 / T_{p}\right)}\right]_{q^{-} / q^{+}=\text {const }}
$$

As was shown in $[24,25]$, this methodology is very robust to most data-distortive effects and thus provides reliable and accurate evaluation of $\Delta \mathrm{h}^{*}$. This is also demonstrated in Fig. 4A, where the corresponding dependences are depicted for all studied $\left(\mathrm{GeSe}_{2}\right)_{y}\left(\mathrm{Sb}_{2} \mathrm{Se}_{3}\right)_{1-\mathrm{y}}$ glasses. Linear fits of these dependences (the slopes) provide the values of $\Delta \mathrm{h}^{*}$. However, the data in Fig. 4A show a curvature at highest heating rates, which is caused by emergence of thermal gradients within the system (sample $\leftrightarrow$ pan $\leftrightarrow$ sensor) - note that in this way the experimental setup can be calibrated [24] for the occurrence of these gradients. Therefore, only the CR cycles data up to the heating rate $30^{\circ} \mathrm{C} \cdot \mathrm{min}^{-1}$ (where the dependences are still linear) were utilized in the determination of $\Delta \mathrm{h}^{*}$; i.e. upper three points in each dependence were omitted from the linear fit. In addition to the CR cycles during which we carefully considered the 
upper temperature limit (to not allow glass degradation during the long term high $\mathrm{T}$ exposure), also several sets of CR cycles were performed, where the upper temperature limit was set so that the glass slowly crystallized during the course of the cycles set. These data are depicted in Fig. 4B together with the results obtained for the fully glassy materials. In accordance with [42], where a similar test was performed for the $\mathrm{Se}_{70} \mathrm{Te}_{30}$ glass, also the present data show that at higher degrees of crystallinity (achieved for the $\left(\mathrm{GeSe}_{2}\right)_{0.3}\left(\mathrm{Sb}_{2} \mathrm{Se}_{3}\right)_{0.7}$ glass, which has highest tendency towards crystallization [11-13]) the dependence exhibits a steeper slope due to the $\mathrm{T}_{\mathrm{g}}$ values being shifted to higher temperatures. Note that this translates in significantly higher apparent activation energy as will be shown later. Moreover, to compare the enthalpy relaxation and viscous flow activation energies, the temperature dependences of $\left(\mathrm{GeSe}_{2}\right)_{\mathrm{y}}\left(\mathrm{Sb}_{2} \mathrm{Se}_{3}\right)_{1-\mathrm{y}}$ glasses viscosities (Table 1 in [22]) were plotted (see Fig. 4C) to determine the corresponding activation energies. As is apparent in Fig. 4C, the dependences are linear over the whole measured range of $\eta$ and as such they can be safely used to estimate the activation energy of viscous flow $\mathrm{E}_{\eta}$.

The data in Fig. 5A show the comparison of structural relaxation activation energies (obtained by DSC from CR3 cycles) and activation energies of viscous flow (obtained from the low-temperature viscosity data) for the $\left(\mathrm{GeSe}_{2}\right)_{\mathrm{y}}\left(\mathrm{Sb}_{2} \mathrm{Se}_{3}\right)_{1-\mathrm{y}}$ and $\left(\mathrm{GeS}_{2}\right)_{\mathrm{y}}\left(\mathrm{Sb}_{2} \mathrm{~S}_{3}\right)_{1-\mathrm{y}}$ systems (the data for the sulfide analog were taken from [23]). Interestingly, both chalcogenide systems exhibit very similar $\Delta \mathrm{h}^{*}$ and $\mathrm{E}_{\eta}$ values, indicating that the similarity in structural ordering dominates over the influence of the lighter/heavier S/Se atoms being incorporated into the glassy matrix. Note that the high $\mathrm{E}_{\eta}$ scatter at low $\mathrm{GeS}_{2}$ content can be attributed to the measurements errors (as reported in [23]). It is also worth stressing that the requirement for having a fully glassy (non-degraded) material is crucial for determination of a correct $\Delta \mathrm{h}^{*}$ value. This is evidenced by the largely higher, incorrect $\Delta \mathrm{h}^{*}$ value obtained for the semicrystalline $\left(\mathrm{GeSe}_{2}\right)_{0.3}\left(\mathrm{Sb}_{2} \mathrm{Se}_{3}\right)_{0.7}$ composition - the discrepancy for the semi-crystalline sample 
is of approx. half the magnitude of the $\Delta \mathrm{h}^{*}$ evolution throughout the whole investigated compositional range. The overall decreasing trend of the activation energies with rising $\mathrm{GeSe}_{2} / \mathrm{GeS}_{2}$ content can be attributed to the increasing base interconnectivity of the glassy matrix (four-fold vs. three-fold bonding) as evidenced by the Raman spectra - note that both nominal compositions in their crystalline form exist as two-dimensional overconstrained networks [43, 44], where the layered structures are connected by weaker intermolecular van der Waals bonds. [4, 20] At higher dimensionality (higher $\mathrm{GeSe}_{2} / \mathrm{GeS}_{2}$ contents) the structure has higher tendency towards cooperative conformation changes, indicated by the larger influenceability by surrounding structure, and as such reacts more slowly/gradually to the temperature changes. On the other hand, higher $\mathrm{Sb}_{2} \mathrm{Se}_{3} / \mathrm{Sb}_{2} \mathrm{~S}_{3}$ contents lead to more segregated structural clusters, which can relax more uniformly, resulting into abrupt structural movements and larger invariance towards the rate of heating/cooling. The corresponding kinetic fragility data (see Eqs. 5 and 6 for the definitions conformable with the Angell fragility concept [45]) are depicted in Fig. 5B:

$$
\begin{gathered}
m_{v i s c .}=\left.\frac{d \log \eta}{d\left(T_{g} / T\right)}\right|_{T=T_{g}} \cong \frac{E_{\eta} / R}{T_{g} \ln (10)} \\
m_{D S C}=\left.\frac{d \log \tau}{d\left(T_{g} / T\right)}\right|_{T=T_{g}} \cong \frac{\Delta h^{*} / R}{T_{g} \ln (10)}
\end{gathered}
$$

where $\eta$ is viscosity, $E_{\eta}$ is the activation energy of the viscous flow evaluated at $T_{g}$ and $\tau$ is the relaxation time. Taking into account the possible errors associated with the viscosity measurements [23], the fragilities of the selenide and sulfide analogs can be considered the same. Also the two types of fragilities (enthalpy and viscosity) determined for each given material are quite similar in accordance with what was already reported [46-48] for a number of glassy materials.

In order to determine the remaining TNM parameters, the simulation-comparative method [49] was employed in accordance with the recently published guide for evaluation of 
enthalpy relaxation measurements [29]. This method requires knowledge of $\Delta \mathrm{h}^{*}$ and $\mathrm{A}$ (this parameter was in the present study estimated by means of curve-fitting) and is based on a comparison of the experimentally determined heights of the normalized relaxation peaks $\mathrm{C}_{\mathrm{p}}{ }^{\max }$ (obtained within a set of CHR cycles) with the results theoretically simulated for various combinations of parameters $x$ and $\beta$. This evaluation is for the $\left(\mathrm{GeSe}_{2}\right)_{0.4}\left(\mathrm{Sb}_{2} \mathrm{Se}_{3}\right)_{0.6}$ composition demonstrated in Fig. 5C. The points correspond to the experimentally obtained heights of the relaxation peak (overshoot) for the data depicted in Fig. 1A and normalized according Eq. 1, the lines then correspond to the theoretical dependences of $\mathrm{C}_{\mathrm{p}}{ }^{\text {max }}$ on the ratio between the heating and cooling rates employed with a set of CHR cycles (each line was simulated for $\Delta \mathrm{h}^{*} / \mathrm{R}=57 \mathrm{kK}, \log (\mathrm{A} / \mathrm{s})=-107$ and a different combination of parameters $\mathrm{x}$ and $\beta)$. The data in Fig. 5C indicate that following TNM parameters can be used for the description of $\left(\mathrm{GeSe}_{2}\right)_{0.4}\left(\mathrm{Sb}_{2} \mathrm{Se}_{3}\right)_{0.6}$ glass relaxation processes: $\mathrm{x} \approx 0.55, \beta \approx 0.70$ (curvature as well as the absolute position of the dependence needs to be considered). Very similar results (ranging within \pm 0.05 for both $\mathrm{x}$ and $\beta$ ) were obtained also for all other studied $\left(\mathrm{GeSe}_{2}\right)_{\mathrm{y}}\left(\mathrm{Sb}_{2} \mathrm{Se}_{3}\right)_{1-\mathrm{y}}$ glasses - the concrete values are listed in the Supplemental online material.

Similar marked indifference of the non-linearity and non-exponentiality features to the compositional changes were already reported [23] for the analogous $\left(\mathrm{GeS}_{2}\right)_{\mathrm{y}}\left(\mathrm{Sb}_{2} \mathrm{~S}_{3}\right)_{1-\mathrm{y}}$ chalcogenide system, where it was ascribed to only one of the involved structural units (namely the $\mathrm{GeS}_{4}$ tetrahedra) carrying the main portion of the relaxation movements and thus effectively reducing the influence of interconnectivity above a certain (quite low) presence threshold. Similar reasoning may be used also in case of the present $\left(\mathrm{GeSe}_{2}\right)_{\mathrm{y}}\left(\mathrm{Sb}_{2} \mathrm{Se}_{3}\right)_{1-\mathrm{y}}$ system, as the Raman spectra from Fig. 3D again show that (at least for the $\mathrm{GeSe}_{2}$-rich glasses) the structural changes during the relaxation process involve additional formation of the $\mathrm{CS}-\mathrm{GeSe}_{4}$ network from the $\mathrm{ES}-\mathrm{GeSe}_{4}$ tetrahedral units present at higher temperatures in 
the undercooled liquid. Despite the indeterminate conclusions obtained for the $\mathrm{GeSe}_{2}$-poor glasses, it still seems that it is the Raman bands for the Ge-based structural units that change during the structural relaxation process. In addition, the Raman bands intensities of asprepared glasses (see Fig. 3B) show that it is only the CS-GeSe 4 structural units that exhibit constant presence in the glassy structure throughout the $\left(\mathrm{GeSe}_{2}\right)_{\mathrm{y}}\left(\mathrm{Sb}_{2} \mathrm{Se}_{3}\right)_{1-\mathrm{y}}$ system, and as such, considering the compositional constancy of $\mathrm{x}$ and $\beta$, the $\mathrm{GeSe}_{4}$ tetrahedral network appears to carry the main portion of the relaxation motions. Note that in this regard we would expect significant changes of the $\mathrm{x}$ and $\beta$ TNM parameters, if for example the $\mathrm{SbSe}_{3 / 2}$ pyramids (the relative occurrence of which decreases with y) were responsible for the relaxation motions. The alternative explanation (employable for both chalcogenide systems) may be associated with the structural network being overconstrained [14] along the whole pseudo-binary line, as the nominal compositions correspond to the actual present structural units ( $\mathrm{GeSe}_{4 / 2}$ tetrahedra and the $\mathrm{SbSe}_{3 / 2}$ pyramids). Since the present Ge-Sb-Se system exhibits similar absolute values of $\mathrm{x}$ and $\beta$ as the previously studied Ge-Sb-S system [23] (where $\mathrm{x} \approx 0.61, \beta \approx 0.72$ ), which are also close to the typical results found for the topologically constrained oxide glasses [50], these values of TNM parameters (note the semiphenomenological nature [51] of the relaxation model) may be considered characteristic for these types of amorphous structural networks - further research is however needed.

\section{Conclusions}

Differential scanning calorimetry and Raman spectroscopy were used to study enthalpy relaxation behavior of the $\left(\mathrm{GeSe}_{2}\right)_{y}\left(\mathrm{Sb}_{2} \mathrm{Se}_{3}\right)_{1-\mathrm{y}}$ chalcogenide glasses along the full glass-forming part of the pseudo-binary compositional line $(y=0.3-0.9)$. The structural

relaxation data were described in terms of the phenomenological TNM model. Increased presence of germanium ( $\mathrm{GeSe}_{2}$ units) lead to a gradual exponential increase of the glass 
transition temperature - from $230{ }^{\circ} \mathrm{C}$ to $350{ }^{\circ} \mathrm{C}$, and to linear decreases of the activation energy for the structural relaxation movements - from $510 \mathrm{~kJ} \cdot \mathrm{mol}^{-1}$ to $340 \mathrm{~kJ} \cdot \mathrm{mol}^{-1}$ - and kinetic fragility (from 55 to 30). The activation energy of structural relaxation was found to be similar to the activation energy of viscous flow. As a side-note, it was shown that semicrystalline materials exhibit slightly higher $T_{g}$, resulting in increased $\Delta h^{*}$. The nonexponentiality and non-linearity kinetic features were found to be invariant with glass composition. All TNM parameters and kinetic fragilities evaluated for the present $\left(\mathrm{GeSe}_{2}\right)_{\mathrm{y}}\left(\mathrm{Sb}_{2} \mathrm{Se}_{3}\right)_{1-\mathrm{y}}$ glassy system were very similar to the results obtained earlier for the $\left(\mathrm{GeS}_{2}\right)_{\mathrm{y}}\left(\mathrm{Sb}_{2} \mathrm{~S}_{3}\right)_{1-\mathrm{y}}$ glasses, which was attributed to the similarly constrained topology of the pseudo-binary compositional lines.

\section{Acknowledgments}

This work was supported by the Czech Science Foundation under project no. 16-10562S.

\section{References}

[1] D.H. Cha, H.J. Kim, H.S. Park, Y. Hwang, J.H. Kim, J.H. Hong, K.S. Lee, Appl. Opt. 49 (2010) 1607.

[2] J.K. Park, J.H. Lee, S.Y. Shin, J.H. Yi, W.H. Lee, N.Y. Kim, Y.G. Choi, Arch. Metall. Mater. 60 (2015) 1205.

[3] L. Petit, N. Carlie, H. Chen, S. Gaylord, J. Massera, G. Boudebs, J. Hu, A. Agarwal, L. Kimerling, K. Richardson, J. Solid State Chem. 182 (2009) 2756.

[4] P. Němec, M. Olivier, E. Baudet, A. Kalendová, P. Benda, V. Nazabal, Mater. Res. Bull. 51 (2014) 176.

[5] Savage JA, Webber PJ, Pitt AM. J Mater Sci. 13 (1978) 859.

[6] M. Olivier, J.C. Tchahame, P. Němec, M. Chauvet, V. Besse, C. Casagne, G. Boudebs, G. Renversez, R. Boidin, E. Baudet, V. Nazabal. Opt. Mater. Express 4 (2014) 525.

[7] I. Quiroga, C. Corredor, F. Bellido, J. Vazquez, P. Villares, R. Garay, J. Non-Cryst. Solids 196 (1996) 183

[8] M.A. Popescu, Non-Crystalline Chalcogenides, Kluwer Academic Publishers, Dordrecht, 2000

[9] Ch Lin, Z. Li, L. Ying, Y. Xu, P. Zhang, S. Dai, T. Xu, Q. Nie, J. Phys. Chem. C. 116 (2012) $5862 \mathrm{e} 5867$

[10] S. Neov, I. Gerasimova, E. Skordeva, D. Arsova, V. Pamukchieva, P. Mikula, P. Lukas, R. Sonntag, J. Mater. Sci. 34 (1999) 3669

[11] N. Clavaguera, M.T. Clavaguera-More, J. Onrubia, J. Mater. Sci. 20 (1985) 3917

[12] N.A. Korepanova, G.M. Orlova, A.V. Pazin, Zhur. Prikl. Khim. 49 (1976) 36 
[13] L. Tichý, H. Tichá, Mat. Chem. Phys. 152 (2015) 1

[14] H. Parnell, D. Furniss, Z. Tang, N.C. Neate, T.M. Benson, A.B. Seddon, J. Am. Ceram. Soc. 101 (2018) 208.

[15] W.H. Lee, J.H. Yi, J.H. Lee, B.J. Park, J.H. Choi, H.J. Kim, Y.G. Choi, Int. J. Appl. Glas. Sci. 8 (2017) 226.

[16] J.H. Lee, J.H. Yi, W.H. Lee, B.J. Park, Y.G. Choi, J. Non-Cryst. Sol. 481 (2018) 21.

[17] H. Wang, G. Wang, D. Shi, X. Shen, Y. Lu, Q. Nie, J. Non-Cryst. Sol. 453 (2016) 108.

[18] E.R. Shaaban, I.B.I. Tomsah. J. Threm. Anal. Calorim. 105 (2011) 191.

[19] E. Baudet, C. Cardinaud, A. Girard, E. Rinnert, K. Michel, B. Bureau, V. Nazabal. J. Non-Cryst. Sol. 444 (2016) 64.

[20] M. Olivier, P. Němec, G. Boudebs, R. Boidin, C. Focsa, V. Nazabal. Opt. Mater. Express 5 (2015) 781.

[21] Y.-L. Gan, L. Wang, X.-Q. Su, S.-W. Xu, X. Shen, R.-P. Wang. J. Raman Spectrosc. 45 (2014) 377.

[22] P. Košt’ál, J. Málek. J. Non-Cryst. Sol. 353 (2007) 2803.

[23] R. Svoboda, J. Málek, M. Liška. J. Non-Cryst. Sol. 479 (2018) 113.

[24] R. Svoboda, Eur. Polym. J. 59 (2014) 180.

[25] R. Svoboda, J. Therm. Anal. Calorim. 121 (2015) 895

[26] R. Svoboda, J. Therm. Anal. Calorim. 118 (2014) 1721

[27] R. Svoboda, J. Non-Cryst. Sol. 408 (2015) 115

[28] G. W. Scherer. Relaxation in Glass and Composites (chapter 9), John Wiley \& Sons (1986) New York.

[29] R. Svoboda, J. Málek, J. Non-Cryst. Solids 378 (2013) 186.

[30] Physico-Chemical Properties of Chalcogens and Binary Chalcogenide Glasses. In: NonCrystalline Chalcogenides. Solid-State Science and Technology Library, vol 8. Springer, Dordrecht (2002)

[31] Wakkad MM, Shokr EK, Mohamed SH. Physica Status Solidi A Appl Res. 2001;183:399-411

[32] L. Petit, N. Carlie, K. Richardson, Y. Guo, A. Schulte, B. Campbell, B. Ferreira, S. Martin, J. Phys. Chem. Sol. 66 (2005) 1788.

[33] V. Nazabal, P. Nemec, A. M. Jurdyc, S. Zhang, F. Charpentier, H. Lhermite, J. Charrier, J. P. Guin, A. Moreac, M. Frumar, J. L. Adam, Thin Solid Films 518 (2010) 4941.

[34] Z. G. Ivanova, E. Cernoskova, V. S. Vassilev, S. V. Boycheva, Mater. Lett. 57 (2003) 1025.

[35] M. Wihl, M. Cardona, J. Tauc, J. Non-Cryst. Sol. 8-10 (1972) 172.

[36] O. Matsuda, K. Inoue, K. Murase, Sol. State Commun. 75 (1990) 303.

[37] K. Jackson, A. Briley, S. Grossman, D. V. Porezag, M. R. Pederson, Phys. Rev. B60 (1999) 14985.

[38] L. Petit, N. Carlie, R. Villeneuve, J. Massera, M. Couzi, A. Humeau, G. Boudebs, K. Richardson, J. Non-Cryst. Sol. 352 (2006) 5413.

[39] A. Q. Tool, J. Am. Ceram. Soc. 29 (1946) 240.

[40] O. S. Naraynaswamy, J. Am. Ceram. Soc. 54 (1971) 491.

[41] C. T. Moynihan, A. J. Easteal, M. A. DeBolt, J. Tucker, J. Am. Ceram. Soc. 59 (1976) 12.

[42] R. Svoboda, P. Honcová, J. Málek, J. Non-Cryst. Solids 356 (2010) 165

[43] Phillips JC. J Non-Cryst Solids 1979;34:153-181

[44] Borisevich VG, Voitsekhovsky VV, Scripachev IV, Vysokochist Vesch. 1991;1:65

[45] C. A. Angell, Science 267 (1995) 1924.

[46] J. Málek, R. Svoboda, P. Pustková and P. Čičmanec, J. Non-Cryst. Sol. 355 (2009) 264.

[47] I. M. Hodge, J. Non-Cryst. Sol. 131-133 (1991) 435. 
[48] M. Chromčiková and M. Liška, J. Therm. Anal. Calorim. 84 (2006) 703.

[49] R. Svoboda, J. Málek, J. Therm. Anal. Cal. 113 (2013) 831

[50] J.C. Mauro, Am. Ceram. Soc. Bull. 90 (2011) 31.

[51] R. Svoboda, Acta Materialia 61 (2013) 4534.

\section{Figure captions}

Fig. 1: A) Example of the CRH cycles set obtained for the $\left(\mathrm{GeSe}_{2}\right)_{0.4}\left(\mathrm{Sb}_{2} \mathrm{Se}_{3}\right)_{0.6}$ glass.

B) Example of the CR cycles set obtained for the $\left(\mathrm{GeSe}_{2}\right)_{0.4}\left(\mathrm{Sb}_{2} \mathrm{Se}_{3}\right)_{0.6}$ glass.

C) Compositional evolution of glass transition temperatures obtained at 1 and $10{ }^{\circ} \mathrm{C} \cdot \mathrm{min}^{-1}$ for the $\left(\mathrm{GeSe}_{2}\right)_{\mathrm{y}}\left(\mathrm{Sb}_{2} \mathrm{Se}_{3}\right)_{1-\mathrm{y}}$ and $\left(\mathrm{GeS}_{2}\right)_{\mathrm{y}}\left(\mathrm{Sb}_{2} \mathrm{~S}_{3}\right)_{1-\mathrm{y}}$ glasses.

D) Example CHR heating scans obtained at $30 / 1 \mathrm{q}^{+} / \mathrm{q}^{-}$ratio for all studied $\left(\mathrm{GeSe}_{2}\right)_{\mathrm{y}}\left(\mathrm{Sb}_{2} \mathrm{Se}_{3}\right)_{1-\mathrm{y}}$ glasses.

Fig. 2: Raman spectra obtained for the $\left(\mathrm{GeSe}_{2}\right)_{y}\left(\mathrm{Sb}_{2} \mathrm{Se}_{3}\right)_{1-\mathrm{y}}$ glasses - split and overlapped at the left- and right-hand sides, respectively. Main types of vibrations are also shown with the red, grey and blue atoms corresponding to $\mathrm{Se}, \mathrm{Ge}$ and $\mathrm{Sb}$, respectively.

Fig. 3: A) Raman spectra obtained for the $\left(\mathrm{GeSe}_{2}\right)_{\mathrm{y}}\left(\mathrm{Sb}_{2} \mathrm{Se}_{3}\right)_{1-\mathrm{y}}$ glasses zoomed in the 125 $250 \mathrm{~cm}^{-1}$ region. Dashed vertical lines indicate the positions of main Raman bands in this region $-150,170,190,200,215$ and $230 \mathrm{~cm}^{-1}$.

B) Compositional evolution of integral intensity for the major deconvoluted Raman bands .

C) Compositional evolution of integral intensity for the minor deconvoluted Raman bands .

D) Comparison of Raman spectra obtained for the two selected $\left(\mathrm{GeSe}_{2}\right)_{y}\left(\mathrm{Sb}_{2} \mathrm{Se}_{3}\right)_{1-\mathrm{y}}$ compositions after either high-temperature quench or sub- $\mathrm{T}_{\mathrm{g}}$ annealing. The vertical blue line indicates the position of Raman band corresponding to the vibration of CS$\mathrm{GeSe}_{4}$ tetrahedra.

Fig. 4: A) Evaluation of $\Delta h^{*}$ from CR cycles according Eq. 4 for all studied $\left(\mathrm{GeSe}_{2}\right)_{\mathrm{y}}\left(\mathrm{Sb}_{2} \mathrm{Se}_{3}\right)_{1-\mathrm{y}}$ glasses. Empty and filled symbols alternate between the concurrent compositions to enhance clarity of the graph.

B) Comparison of $\ln \left(\mathrm{q}^{-}\right) / \mathrm{T}^{-1}$ dependences for fully amorphous and partially crystalline $\mathrm{y}=0.3,0.4$ and 0.5 compositions.

C) Evaluation of $\mathrm{E}_{\eta}$ for all studied $\left(\mathrm{GeSe}_{2}\right)_{\mathrm{y}}\left(\mathrm{Sb}_{2} \mathrm{Se}_{3}\right)_{1-\mathrm{y}}$ glasses - data taken from [22]. Empty and filled symbols alternate between the concurrent compositions to enhance clarity of the graph.

Fig. 5: A) Compositional evolution of $\Delta \mathrm{h}^{*}$ and $\mathrm{E}_{\eta}$ for the $\left(\mathrm{GeSe}_{2}\right)_{\mathrm{y}}\left(\mathrm{Sb}_{2} \mathrm{Se}_{3}\right)_{1-\mathrm{y}}$ and $\left(\mathrm{GeS}_{2}\right)_{\mathrm{y}}\left(\mathrm{Sb}_{2} \mathrm{~S}_{3}\right)_{1-\mathrm{y}}$ glasses. Red point corresponds to the evaluation of partially crystalline material.

B) Compositional evolution of kinetic fragilities calculated from the calorimetric and viscosity data for the $\left(\mathrm{GeSe}_{2}\right)_{\mathrm{y}}\left(\mathrm{Sb}_{2} \mathrm{Se}_{3}\right)_{1-\mathrm{y}}$ and $\left(\mathrm{GeS}_{2}\right)_{\mathrm{y}}\left(\mathrm{Sb}_{2} \mathrm{~S}_{3}\right)_{1-\mathrm{y}}$ glasses.

C) Example of the evaluation of TNM parameters $\mathrm{x}$ and $\beta$ for the $\left(\mathrm{GeSe}_{2}\right)_{0.4}\left(\mathrm{Sb}_{2} \mathrm{Se}_{3}\right)_{0.6}$ glass by using the simulation-comparative method. 
Table 1

Lower and upper temperature limits for the CR and CHR cyclic experiments.

\begin{tabular}{|c|c|c|}
\hline $\begin{array}{c}\mathrm{GeSe}_{2} \\
\text { content }\end{array}$ & $\begin{array}{c}\mathrm{T}_{\text {lower }} \\
{ }^{\circ} \mathrm{C}\end{array}$ & $\begin{array}{c}\mathrm{T}_{\text {upper }} \\
{ }^{\circ} \mathrm{C}\end{array}$ \\
\hline 0.3 & 180 & 257 \\
\hline 0.4 & 180 & 270 \\
\hline 0.5 & 190 & 310 \\
\hline 0.6 & 190 & 350 \\
\hline 0.7 & 190 & 370 \\
\hline 0.8 & 190 & 380 \\
\hline 0.9 & 190 & 440 \\
\hline
\end{tabular}


Fig 1
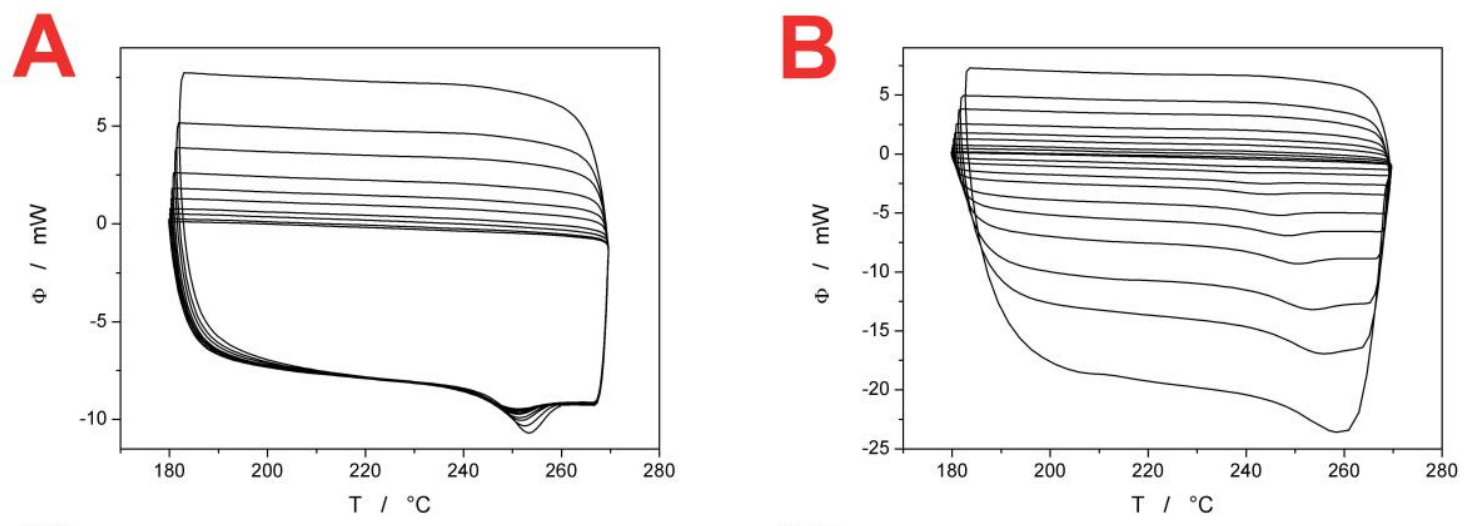

C

D
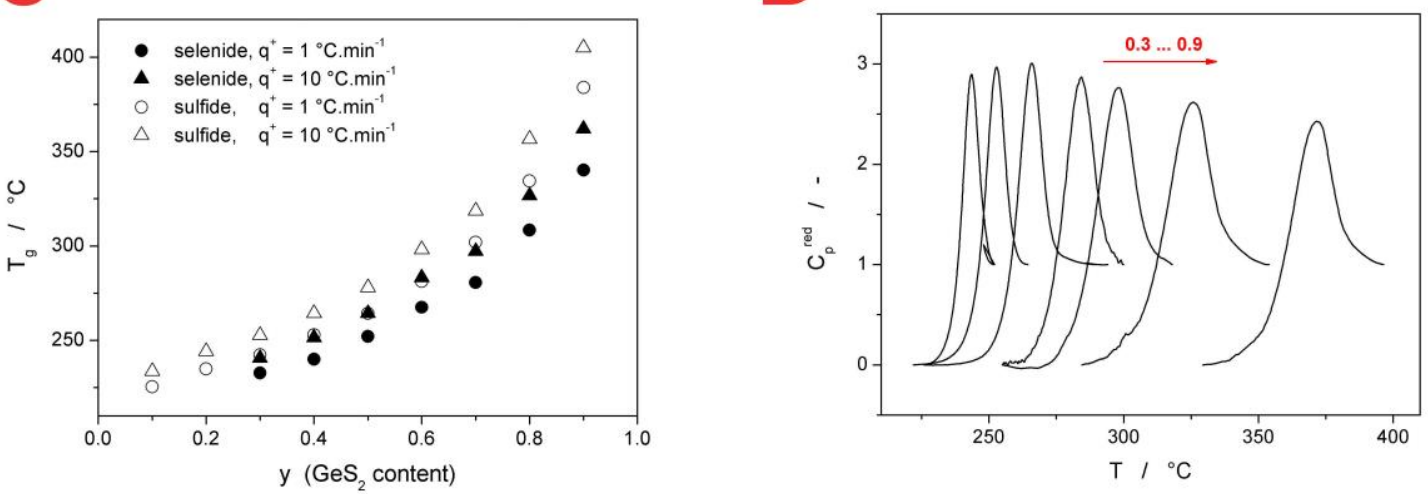
Fig 2
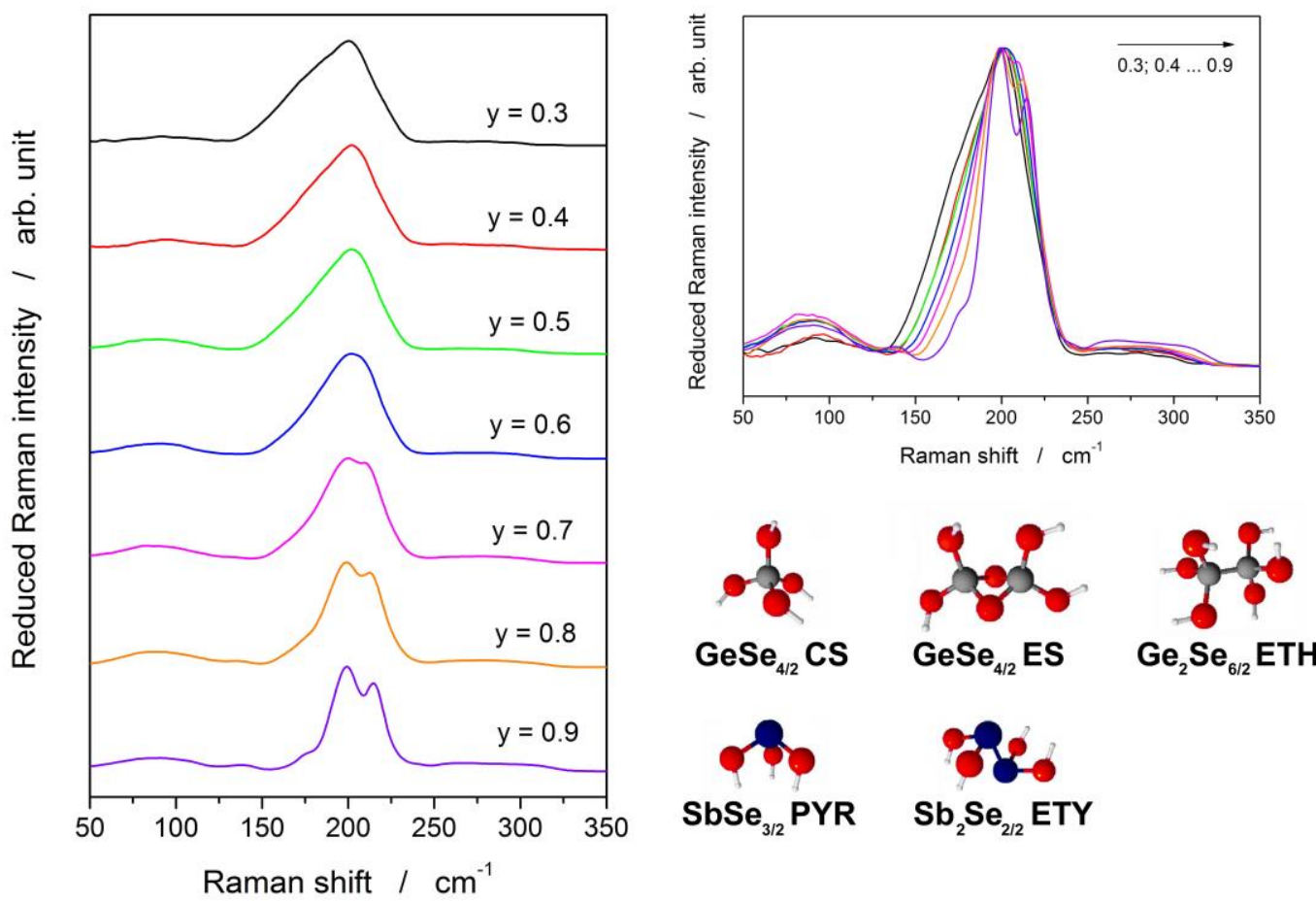

$\mathrm{SbSe}_{3 / 2}$ PYR $\mathrm{Sb}_{2} \mathrm{Se}_{2 / 2}$ ETY

Raman shift $/ \mathrm{cm}^{-1}$ 
Fig 3
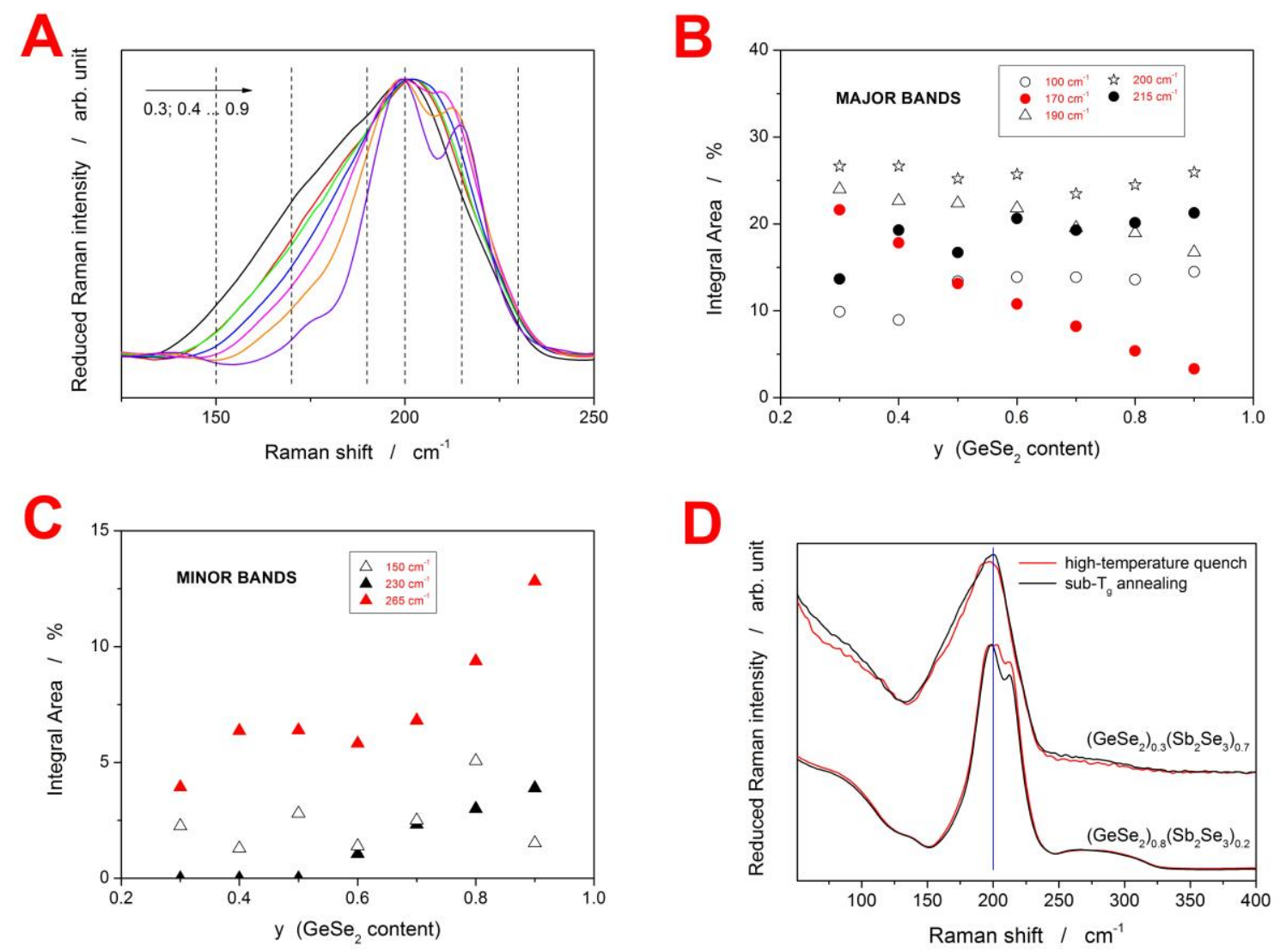
Fig 4
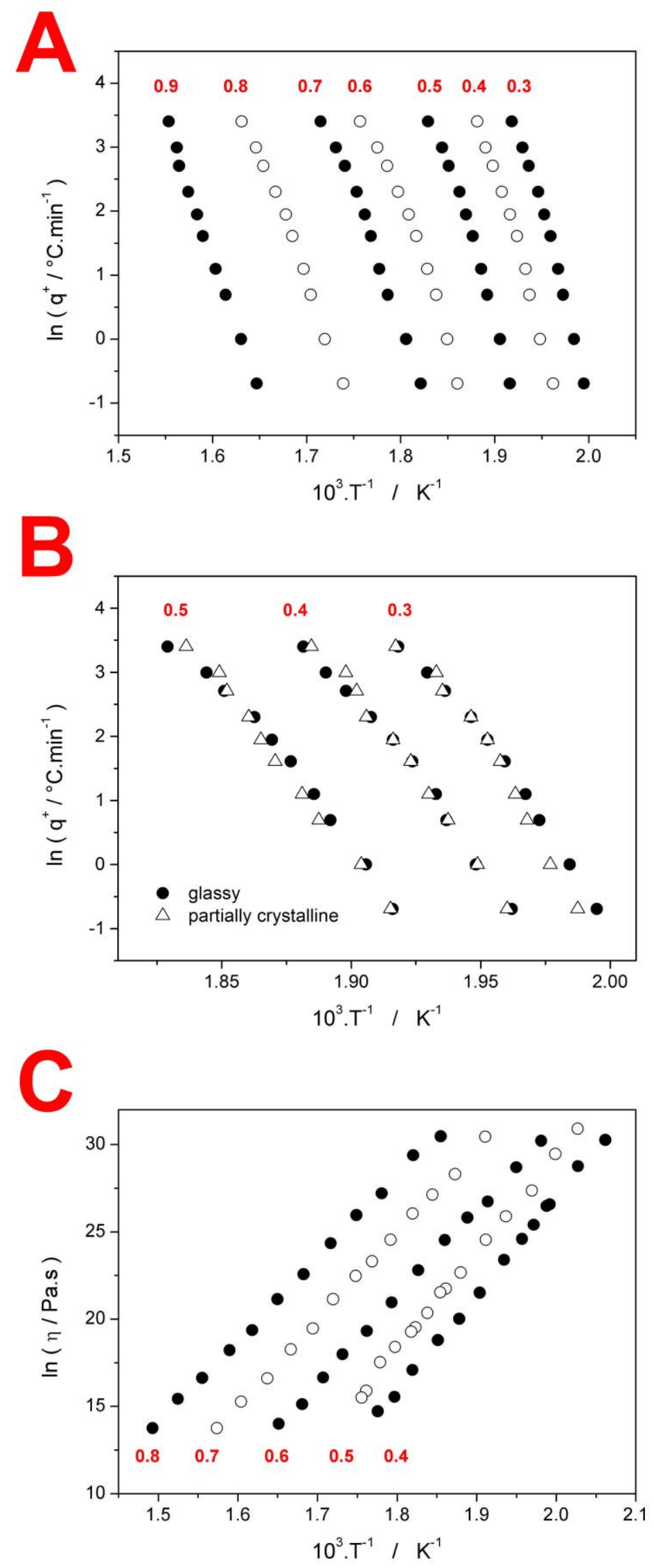
Fig 5

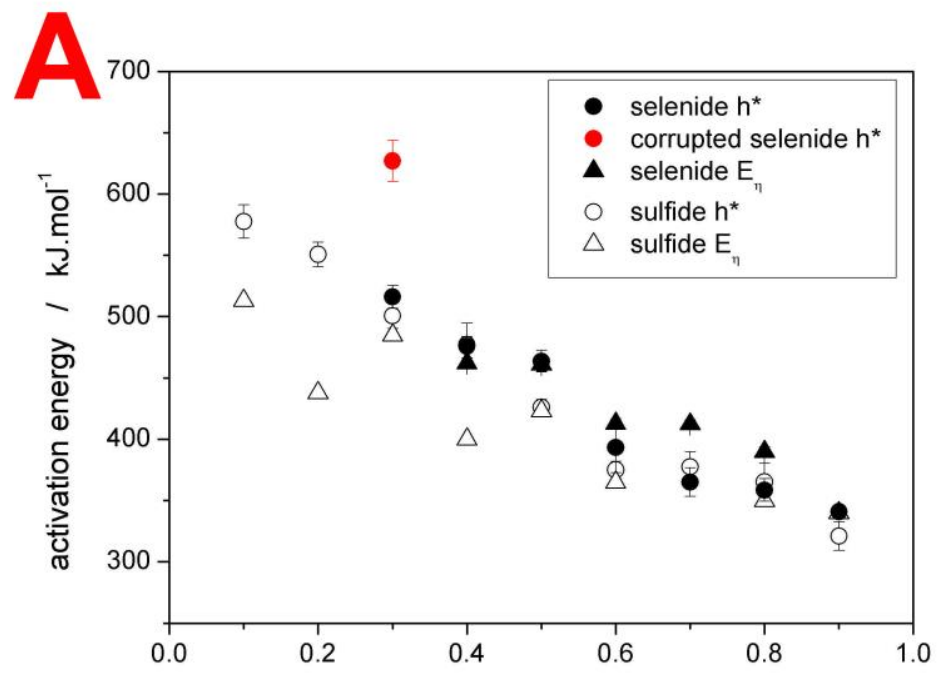

at. $\%$ of $\mathrm{GeSe}_{2}$ and $\mathrm{GeS}_{2}$
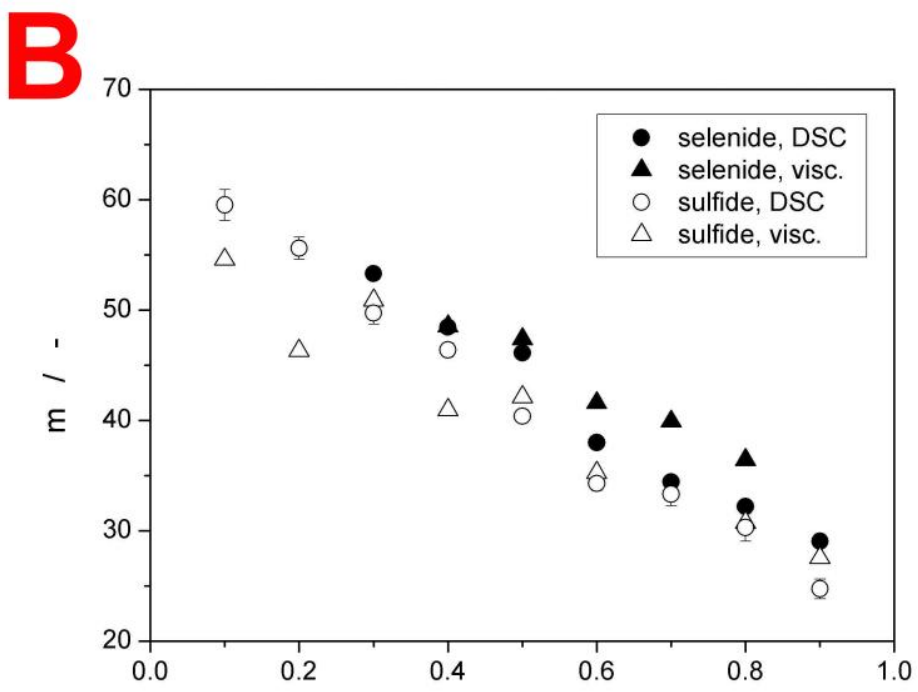

at. \% of $\mathrm{GeSe}_{2}$ and $\mathrm{GeS}_{2}$

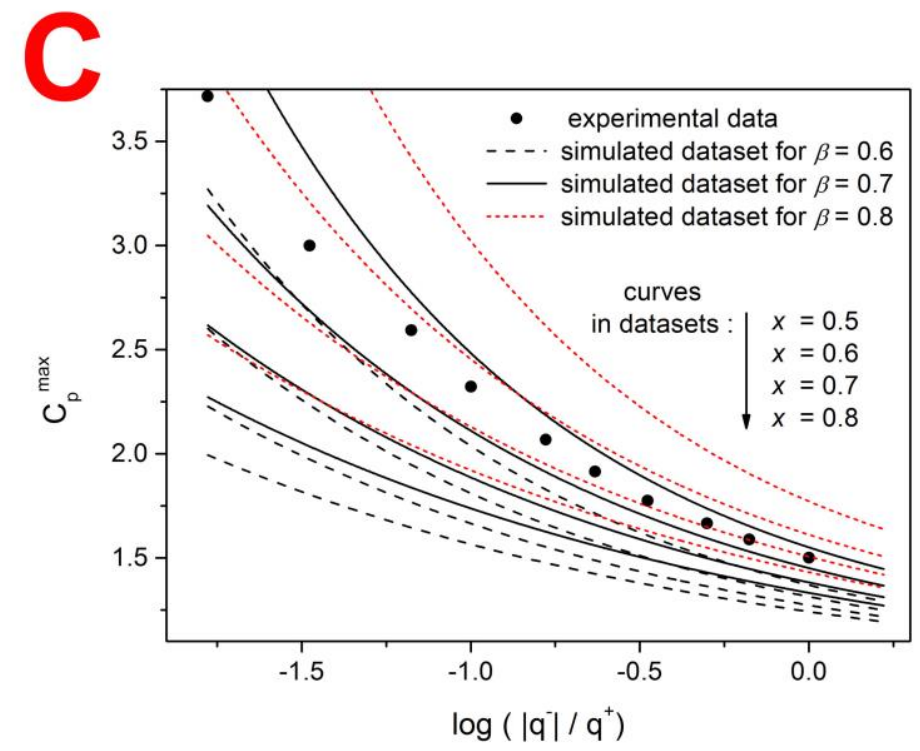

